Journal of Engineering and Applied Sciences 15 (1): 335-340, 2020

ISSN: 1816-949X

(C) Medwell Journals, 2020

\title{
The Effect of the Dimensions of the Body on the Radar Cross Section (RCS)
}

\author{
Osama Karim Mohammed \\ Technical Institute of Amara, Southern Technical University, Basra, Iraq
}

\begin{abstract}
Scattering is the reflection of electromagnetic radiation in various directions, as a result of gas and dust particles located in space. The form of electromagnetic scattering problem for the Body of Revolution (BOR) that are generated by the rotation of an axis called the axis of symmetry because of the symmetry advantages, surface currents can be represented by a fourier series to express the basic function of the current and the test function. Scattering problem can be solved by the equations of the Electric Field Integral Equation (EFIE) and Magnetic Field Integral Equation (MFIE), Galerkin approach was chosen as a method of calculation in this field. The principle of this method depends on the choice of the weighting function that is equal to the complex conjugate of the basis function. The basis function is selected accurately to obtain good results for the scattering problem which is difficult to solve theoretically due to the special boundary conditions for this problem, This method requires a large number of basis functions and testing functions to suit the exact solution. in addition to the Method of Moments (MOM) which is a numerical method for solving electrical and magnetic integrals equations which can calculate the Radar Cross Section (RCS) for the conducting bodies.
\end{abstract}

Key words: Electromagnetic scattering, conducting bodies, body of revolution, method of moment, radar cross section, canjugate

\section{INTRODUCTION}

Electromagnetic waves are related patterns of the electric and magnetic fields, they are perpendicular to each other, i.e., the angle between them is $90^{\circ}$. On the other hand, the two fields are perpendicular to the line of wave propagation, since, the electromagnetic wave has a direction of propagation that does not change unless it hits a surface. These waves are generated by the vibrate of electric charges and move them forward and backward and travel through space at the speed of light which is $300000 \mathrm{~km} \mathrm{sec}^{-1}$. Flat waves that travel through space in straight lines are the simplest types of electromagnetic waves, this result there two types of fields called the first near field and the other is called the far field. Therefore, the wave is another form of the far field resulting from the change of electric field and magnetic field.

Electromagnetic radiation is classified according to its wavelength. The electromagnetic spectrum is composed according to increasing frequency and decreasing wavelength. It consists of radio waves, followed by microwaves, infrared, visible light, ultraviolet radiation, followed by x-rays and finally gamma rays (Kumar and Dangi, 2016).

The matter of Electromagnetic (EM) Scattering and Radiation from bodies have been studied by many researchers. One of the most efficient techniques to handle the treatment problem of scattering is the Surface Integral Equation (SIE) which was developed to analyze the properties of the scattering of these objects when it own describe the Body of Revolution (BOR), body of revolution can be defined as the body that is produced by a curved rotation called a curved around a particular axis called the axis of symmetry (Rui et al., 2010). This body is a three-dimensional target and is transformed from a three-dimensional problem into a number of binary issues using the advantage of symmetry as well as reducing the time and storage of the desired computer to resolve this problem (Rao et al., 2017). A pair of integrative equations is formulated using Maxwell's equations and boundary conditions and the Greens theory which known as an electric field in a vacuum point due to the dipole at another point in space.

The Method of Moment (MOM) was used in such problem to differentiate them by providing accurate results as well as to include all the radiation conditions of regular and irregular objects (Medgyesi-Mitschang and Wang, 1983). The Galerken approaches were chosen to be more appropriate in selecting the weight function of the solution, especially after the development of high-speed computer technology and high precision (King and Harrison, 1971).

The radar is a system that uses electromagnetic waves to identify the distance, height, direction and velocity of stationary and mobile objects such as aircraft and ships, etc. (Fig. 1).

The transmitter emits radio waves reflected by the target recognized by the receiver. The back-to-back waves are weak and the receiver amplifies those waves, making it easier for the detector to distinguish waves from its path from other waves such as sound waves and light waves (Sevgi et al., 2013). 


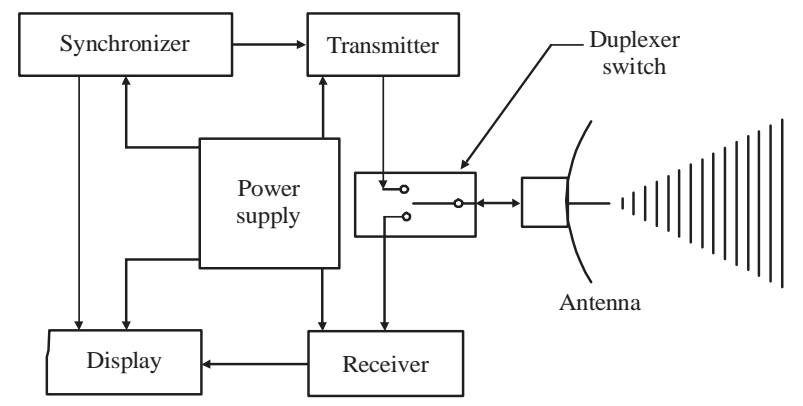

Fig. 1: A simple image of a radar

The amount of energy that bounces from the target of the transmitted radar depends on four main factors (Khan et al., 2012):

- Energy sent towards the target

- The amount of energy that collides with the target and goes back towards the radar

- The amount of energy received by the antenna

- The time period in which the radar is oriented towards the target

The use of radar is not confined to war zones but the use of radar in many other fields, especially the use of navigation and air navigation to prevent collision of ships and aircraft with each other, used radar to control of traffic, as well as in meteorology and scientific and astronomical studies such as satellites.

\section{MATERIALS AND METHODS}

Radar Cross Section (RCS): The Radar Cross Section (RCS) symbolized by the symbol $(\delta)$ is defined as a measure of the scattered energy towards the receiver of radar depends on the intensity of the incident field energy, the RCS is (Divyalakshmi et al., 2018):

$$
\sigma=4 \pi \lim _{\mathrm{R} \rightarrow \infty} \mathrm{R}^{2} \frac{\left|\overrightarrow{\mathrm{E}}^{s}\right|^{2}}{\left|\overrightarrow{\mathrm{E}}^{\mathrm{i}}\right|^{2}}=4 \pi \lim _{\mathrm{R} \rightarrow \infty} \mathrm{R}^{2} \frac{\left|\overrightarrow{\mathrm{H}}^{\mathrm{s}}\right|^{2}}{\left|\overrightarrow{\mathrm{H}}^{\mathrm{i}}\right|^{2}}
$$

where, $\overrightarrow{\mathrm{E}}^{\mathrm{s}}, \overrightarrow{\mathrm{H}}^{\mathrm{s}}$ are the electrical and magnetic fields (scattering) and which produced because of the target, while represent electrical and magnetic fields incident and these fields measured in units (Volt/Meter) and represents the distance between target and radar receiver measured in meter. The value of RCS depends on the function of many factors (Hamham et al., 2017):

- The shape and physical dimension of the target

- The properties of the target material

- Polarization of incident and received waves

- Radar wave frequency
There are commonly used terms in radar measurements (Mono-Static) and (Bi-Static). The first is due to the radar measurements in which the radar and receiver are in the same angle (the transmission and receiving angle is one. While the second term is due to the measurements in which the radar transmitter and receiver are at different angles (Boadu et al., 2017).

Scattering problem: The Electric Field Integral Equation (EFIE) for the electric current $\bar{J}$ induced on Surface $S$ of perfectly conducting body of revolution by incident Electric field $\overline{\mathrm{E}}^{\text {inc }}$ satisfying boundary condition that the tangential electric field must be vanish at the surface:

$$
-\hat{\mathrm{n}}^{*} \overline{\mathrm{E}}_{\mathrm{tan}}^{\mathrm{s}}(\mathrm{r})=\hat{\mathrm{n}} * \overline{\mathrm{E}}_{\mathrm{tan}}^{\mathrm{inc}}
$$

Where:

$\hat{\mathrm{n}} \quad$ : Denoted the unit vector normal to the surface of conductor S

$\left(\overline{\mathrm{E}}^{\mathrm{s}}\right)$ : The scattered field due to $\overline{\mathrm{J}}$ on $\mathrm{S}$

$\left(\bar{E}_{\text {tan }}^{\text {inc }}\right)$ : Denotes the tangential component of the fields on the surfaces

The scattered field that produced by equivalent current can be expressed in terms of the vector $\bar{A}$ and scalar potentials $(\varphi)$ (Madheswaran and Kumar, 2012):

$$
\begin{gathered}
\overline{\mathrm{E}}^{\mathrm{s}}(\overline{\mathrm{r}})=-\mathrm{j} \omega \overline{\mathrm{A}}(\overline{\mathrm{r}})-\nabla \varphi(\overline{\mathrm{r}}) \\
\overline{\mathrm{A}}\left(\overline{\mathrm{r}}^{\prime}\right)=\mu \int \mathrm{J}\left(\overline{\mathrm{r}}^{\prime}\right) \mathrm{G}\left(\overline{\mathrm{r}}, \overline{\mathrm{r}}^{\prime}\right) d \dot{s}^{\prime} \\
\varphi\left(\overline{\mathrm{r}}^{\prime}\right)=\frac{1}{\epsilon} \int \sigma(\overline{\mathrm{r}}) \mathrm{G}\left(\overline{\mathrm{r}}, \overline{\mathrm{r}}^{\prime}\right) d \dot{s}^{\prime} \\
G\left(\overline{\mathrm{r}}, \overline{\mathrm{r}}^{\prime}\right)=\frac{\mathrm{e}^{-\mathrm{j} k\left|\overline{\mathrm{r}}-\overline{\mathrm{r}}^{\prime}\right|}}{\mathrm{r} \pi\left|\overline{\mathrm{r}}-\overline{\mathrm{r}}^{\prime}\right|}
\end{gathered}
$$

where, $\left(\bar{r}, \bar{r}^{\prime}\right)$ is the free space scalar Green's function and for BOR (Fig. 2 and 3): 


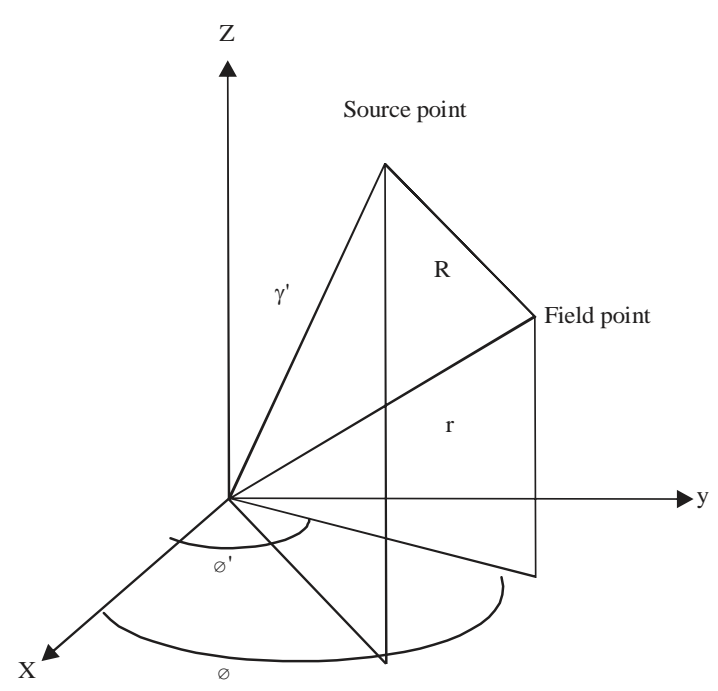

Fig. 2: Coordinate of Body of Revolution (BOR)

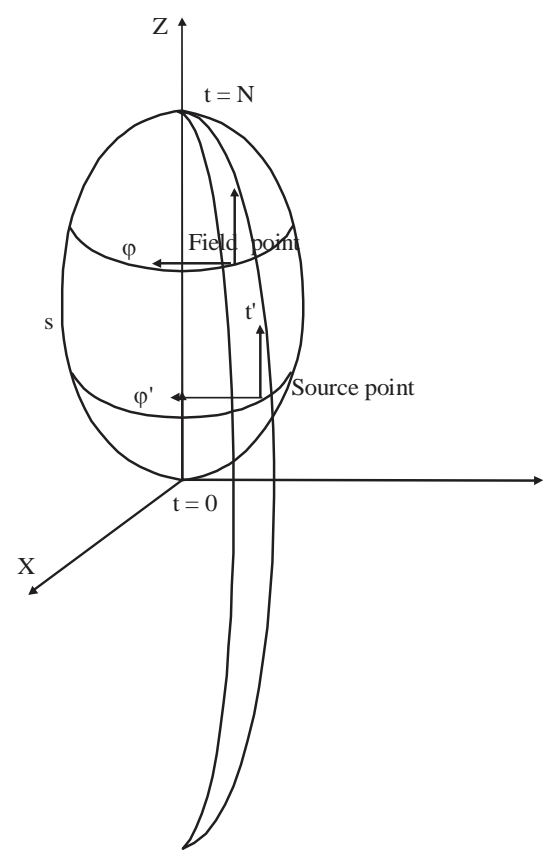

Fig. 3: Geometry Body of Revolution (BOR)

$$
\mathrm{R}=\left|\overline{\mathrm{r}}-\overrightarrow{\mathrm{r}}^{\prime}\right|=\sqrt{\left(\rho-\bar{\rho}^{2}+\left(\mathrm{Z}-\mathrm{Z}^{\prime}\right)^{2} 2 \rho \rho^{\prime}\left(1-\cos \left(\varnothing-\varnothing^{\prime}\right)\right)\right.}
$$

where, $\mathrm{R}$ is the numerical value of the vector relative location that connects between source and field point:

$$
\varphi\left(\overrightarrow{\mathrm{r}}^{\prime}\right)=\frac{1}{4 \pi \varepsilon} \int_{\mathrm{s}} \sigma\left(\overrightarrow{\mathrm{r}}^{\prime}\right) \mathrm{G}\left(\overline{\mathrm{r}}, \overrightarrow{\mathrm{r}}^{\prime}\right) \mathrm{ds}
$$

where, $\varphi\left(\vec{r}^{\prime}\right)$ is the electric charge which related to the electric current by the continuity equation:

$$
\sigma\left(\mathrm{r}^{\prime}\right)=\frac{\mathrm{j}}{\omega} \bar{\nabla}_{\mathrm{s}}^{\prime} \cdot \bar{J}\left(\overline{\mathrm{r}}^{\prime}\right)
$$

Azimuthally components $(\hat{\varphi})$ vector units of the tangential $(\hat{t})$ are linked to the relationship:

$$
\hat{\mathrm{n}}=\hat{\varnothing} \times \hat{\mathrm{t}}
$$

By combining Eq. 1 into Eq. 8 the EFIE can be written as:

$$
\hat{n} \times \bar{E}_{\tan }^{\text {inc }}=\hat{n} \times\left[\frac{j \omega \mu}{4 \pi} \int_{\mathrm{s}} \bar{J}(r) G\left(\bar{r}, \bar{r}^{\prime}\right) d s-\frac{j \nabla}{4 \pi \omega \varepsilon} \int_{\mathrm{s}} \nabla^{\prime} \cdot \bar{J}(r) n G\left(\bar{r}, \vec{r}^{\prime}\right) d s\right]
$$

Where:

$\omega \quad:$ The radian frequency

$\mu$ and $\varepsilon$ : The permeability and permitzivity of the medium respectively denotes a field point denotes a source point

Equation 10 can be represent of term operator as:

$$
\mathrm{L}(\overline{\mathrm{J}})=\overline{\mathrm{E}}_{\mathrm{tan}}^{\mathrm{inc}}
$$

where, $\mathrm{L}$ is the integral deferential operator defined as (Areebi, 2016):

$$
\mathrm{L}(\overline{\mathrm{X}})=\int_{\mathrm{s}} \mathrm{j} \omega \mu \overline{\mathrm{X}}\left(\mathrm{r}^{\prime}\right) \frac{\mathrm{e}^{-\mathrm{j}|\mathrm{r}| \overline{\mathrm{r}} \overrightarrow{\mathrm{r}} \mid}}{4 \pi|\overline{\mathrm{r}}-\overrightarrow{\mathrm{r}}|} \mathrm{ds}-\frac{\nabla}{\mathrm{j} \omega \varepsilon} \int_{\mathrm{s}} \nabla^{\prime} \cdot \overline{\mathrm{X}}\left(\mathrm{r}^{\prime}\right) \frac{\mathrm{e}^{-\mathrm{j}|\mathrm{r}| \overline{\mathrm{r}} \mid}}{4 \pi|\overline{\mathrm{r}}-\overrightarrow{\mathrm{r}}|} \mathrm{ds}
$$

The solution of this Eq. 12 is obtained numerically by using Method of Moments (MOM) and due to the rotational symmetry of the body can use the Fourier series to represent this function:

$$
\begin{gathered}
\bar{J}\left(\overline{r^{\prime}}\right)=\sum_{m j}\left(I_{m j}^{t} \overline{J_{m j}^{t}}\left(\overline{r^{\prime}}\right) \hat{t}^{\prime}+I_{m j}^{\varphi} \overline{J_{m j}^{\varphi}}\left(\overline{r^{\prime}}\right) \hat{\varphi}^{\prime}\right) \\
J_{m j}^{t}\left(\overline{r^{\prime}}\right)=\rho^{\prime} F\left(t^{\prime}\right) e^{j \mathrm{~m} \varphi^{\prime}}
\end{gathered}
$$

$\mathrm{J}_{\mathrm{mj}}^{\mathrm{t}}$ and $\mathrm{I}_{\mathrm{mj}}^{\varnothing}$ are the unknown coefficient can be determined, the coefficients obtain by $\mathrm{N}$ weighted faction:

$$
\begin{gathered}
\overline{\mathrm{W}}\left(\mathrm{r}^{\prime}\right)=\sum_{\mathrm{mj}}\left(\mathrm{I}_{\mathrm{mj}}^{\mathrm{t}} \overline{\mathrm{W}}_{\mathrm{mj}}^{\mathrm{t}}\left(\overline{\mathrm{r}^{\prime}}\right) \hat{t}^{\prime}+\mathrm{I}_{\mathrm{mj}}^{\varphi} \mathrm{W}_{\mathrm{mj}}^{\varphi} \overline{\mathrm{r}^{\prime}} \hat{)} \hat{\varphi}^{\prime}\right) \\
\mathrm{W}_{\mathrm{mj}}^{\mathrm{t}}(\overline{\mathrm{r}})=\rho \mathrm{F}\left(\mathrm{t}^{\prime}\right) \mathrm{e}^{-\mathrm{jm} \varphi}
\end{gathered}
$$

According to Galerkin's approach $\left(\overline{\mathrm{W}}=\mathrm{j}^{*}\right)$ and $\mathrm{J}$ *are the orthogonal vector to the surface S (Resende et al., 2015). 
After testing each side of Eq. 10 obtains the generalize matrix equation:

Where:

$$
\left[\mathrm{Z}_{\mathrm{n}}\right]\left[\mathrm{I}_{\mathrm{n}}\right]=\left[\mathrm{V}_{\mathrm{n}}\right]
$$

$V_{n}$ and $I_{n}$ : The excitation and unknown coefficients matrix

$\mathrm{Z}_{\mathrm{n}} \quad$ : The impedance matrix of the body given by Kong et al. (2016)

$$
\begin{gathered}
{\left[\mathrm{V}_{\mathrm{n}}\right]=\left[\left[<\mathrm{W}_{\mathrm{ni}}^{\mathrm{t}}, \mathrm{E}^{\mathrm{inc}}\right],\left[\mathrm{W}_{\mathrm{ni}}^{\varnothing}, \mathrm{E}^{\mathrm{inc}}\right]\right]} \\
{\left[\mathrm{I}_{\mathrm{n}}\right]=\left[\left[\mathrm{I}_{\mathrm{ni}}^{\mathrm{t}}\right],\left[\mathrm{I}_{\mathrm{ni}}^{\varnothing}\right]\right]} \\
{\left[\mathrm{Z}_{\mathrm{n}}\right]=\left[\begin{array}{cc}
\mathrm{Z}_{\mathrm{n}}^{\mathrm{tt}} & \mathrm{Z}_{\mathrm{n}}^{\mathrm{t} \varnothing} \\
\mathrm{Z}_{\mathrm{n}}^{\varnothing \mathrm{t}} & \mathrm{Z}_{\mathrm{n}}^{\varnothing \varnothing}
\end{array}\right]}
\end{gathered}
$$

The $\mathrm{Z}$ sub matrices given by form:

$$
\begin{aligned}
\left.\left(\mathrm{Z}_{\mathrm{n}}^{\alpha \beta}\right)_{\mathrm{ij}}=\int_{0}^{\mathrm{N}} \mathrm{dt} \int_{0}^{02 \pi} \rho \mathrm{d} \varphi \int_{0}^{\mathrm{N}} \mathrm{d}^{\prime} \mathrm{t} \int_{0}^{02 \pi} \rho^{\prime} \mathrm{d} \varphi^{\prime}\right)\left\{\mathrm{Jw} \mu\left(\mathrm{W}_{\mathrm{ni}}^{\alpha} \cdot J_{\mathrm{nj}}^{\beta}\right)+\frac{1}{\mathrm{j} \delta \varepsilon}\left(\nabla \cdot \mathrm{W}_{\mathrm{nj}}^{\alpha}\right)\left(\nabla^{\prime} \cdot J_{\mathrm{ni}}^{\beta}\right)\right\} \mathrm{G}\left(\mathrm{r}^{\prime}, \overline{\mathrm{r}}^{\prime}\right) \\
\nabla^{\prime} \cdot \mathrm{J}=\frac{1}{\rho^{\prime}} \times \frac{\partial}{\partial^{\prime} \mathrm{t}}\left(\rho^{\prime} \mathrm{J}_{\mathrm{nj}}^{\mathrm{t}} \times \hat{\mathrm{u}}_{\mathrm{t}}^{\prime}\right)+\frac{1}{\rho^{\prime}} \times \frac{\partial}{\partial^{\prime} \mathrm{t}}\left(\mathrm{J}_{\mathrm{nj}}^{\varnothing} \times \hat{\mathrm{u}}_{\varnothing}^{\prime}\right) \\
\nabla^{\prime} \cdot \mathrm{W}=\frac{1}{\rho} \times \frac{\partial}{\partial \mathrm{t}}\left(\rho \mathrm{W}_{\mathrm{nj}}^{\mathrm{t}} \times \hat{\mathrm{u}}_{\mathrm{t}}\right)+\frac{1}{\rho} \times \frac{\partial}{\partial \varnothing}\left(\mathrm{W}_{\mathrm{ni}}^{\varnothing} \times \hat{\mathrm{u}}_{\varphi}\right)
\end{aligned}
$$

Using Eq. 8, 20, 21 and definition of Green's function into Eq. 19 to obtain the explicit form of $\mathrm{Z}$ sub matrices of Eq. 18:

$$
\begin{aligned}
& \left(\mathrm{Z}_{\mathrm{n}}^{\mathrm{tt}}\right)_{\mathrm{ij}}=\sum_{\mathrm{p}=1}^{4} \sum_{\mathrm{q}=1}^{4}\left\{J \mathrm{JW} \mathrm{T}_{\mathrm{p}} \mathrm{T}_{\mathrm{q}}\left[\frac{\mathrm{gn}+1+\mathrm{gn}-1}{2}+\cos v_{\mathrm{p}} \cos v_{\mathrm{q}} \mathrm{g}_{\mathrm{n}}\right]+\frac{1}{\mathrm{JW} \boldsymbol{E}} \mathrm{T}_{\mathrm{p}}{ }^{\prime} \mathrm{T}_{\mathrm{q}}{ }_{\mathrm{q}} \mathrm{gn}\right\} \\
& \left(\mathrm{Z}_{\mathrm{n}}^{\mathrm{t}}\right)_{\mathrm{ij}}=\sum_{\mathrm{p}=1}^{4} \sum_{\mathrm{q}=1}^{4}\left\{-\mathrm{W} \mu \mathrm{T}_{\mathrm{p}} \mathrm{T}_{\mathrm{q}}\left[\sin v_{\mathrm{p}} \frac{\mathrm{gn}+1-\mathrm{gn}-1}{2}\right]+\frac{1}{\mathrm{Jw} \varepsilon \rho \mathrm{q}} \mathrm{T}_{\mathrm{p}} \mathrm{T}_{\mathrm{q}} \mathrm{gn}\right\} \\
& \left(\mathrm{Z}_{\mathrm{n}}^{\varphi t}\right)_{\mathrm{ij}}=\sum_{\mathrm{p}=1}^{4} \sum_{\mathrm{q}=1}^{4}\left\{\mathrm{~W} \mu \mathrm{T}_{\mathrm{p}} \mathrm{T}_{\mathrm{q}}\left[\sin v_{\mathrm{p}} \frac{\mathrm{gn}+1-\mathrm{gn}-1}{2}\right]-\frac{1}{\mathrm{Jw} \rho \rho \mathrm{q}} \mathrm{T}_{\mathrm{p}} \mathrm{T}_{\mathrm{q}} \mathrm{gn}\right\}
\end{aligned}
$$

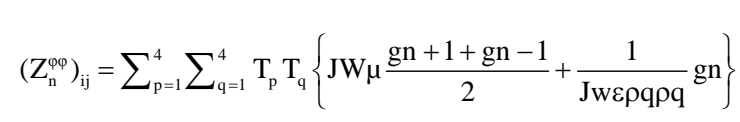

$$
\begin{aligned}
& \mathrm{G}_{\mathrm{n}}=\frac{\pi}{\mathrm{M}} \sum_{\mathrm{m}=1}^{\mathrm{M}} \operatorname{cosn} \varphi_{\mathrm{m}} \mathrm{F}\left(\varphi_{\mathrm{m}}\right)
\end{aligned}
$$

Equation 22-25 can be write in final form (Huddleston et al., 1986):

$$
\begin{aligned}
& \left(Z_{n}^{\mathrm{t}}\right)_{\mathrm{ij}}=\sum_{\mathrm{p}=1}^{4} \sum_{\mathrm{q}=1}^{4}\left[j \omega \mu \mathrm{T}_{\mathrm{p}} \mathrm{T}_{\mathrm{q}}\left(\begin{array}{l}
\sin \left(\mathrm{v}_{\mathrm{p}}\right) \sin \left(\mathrm{v}_{\mathrm{q}}\right) \frac{\mathrm{G}_{\mathrm{n}+1}+\mathrm{G}_{\mathrm{n}-1}}{2} \\
+\cos \left(v_{\mathrm{p}}\right) \cos \left(\mathrm{v}_{\mathrm{q}}\right) \mathrm{G}_{\mathrm{n}}
\end{array}\right)+\frac{1}{j \omega \varepsilon} \mathrm{T}_{\mathrm{p}}^{\prime} \mathrm{T}_{\mathrm{q}}^{\prime} \mathrm{G}_{\mathrm{n}}\right] \\
& \left(\mathrm{Z}_{\mathrm{n}}^{\mathrm{tq}}\right)_{\mathrm{ij}}=\sum_{\mathrm{p}=1}^{4} \sum_{\mathrm{q}=1}^{4}\left[-\omega \mu \mathrm{T}_{\mathrm{p}} \mathrm{T}_{\mathrm{q}}\left[\sin \left(\mathrm{v}_{\mathrm{p}}\right) \frac{\mathrm{G}_{\mathrm{n}+1}-\mathrm{G}_{\mathrm{n}-1}}{2}\right]+\frac{1}{J \omega \varepsilon \rho_{\mathrm{q}}} \mathrm{T}_{\mathrm{p}}^{\prime} \mathrm{T}_{\mathrm{q}} \mathrm{G}_{\mathrm{n}}\right] \\
& \left(Z_{n}^{\varphi t}\right)_{i j}=\sum_{p=1}^{4} \sum_{q=1}^{4}\left[\omega \mu T_{p} T_{q}\left[\sin \left(v_{q}\right) \frac{G_{n+1}-G_{n-1}}{2}\right]-\frac{1}{J \omega \varepsilon \rho_{p}} T_{p} T_{q}^{\prime} G_{n}\right] \\
& \left(Z_{n}^{\phi \varphi}\right)_{i j}=\sum_{p=1}^{4} \sum_{q=1}^{4} T_{p} T\left[j \omega \mu \frac{G_{n+1}+G_{n-1}}{2}+\frac{1}{j \omega \varepsilon \rho_{p} \rho_{q}} G_{n}\right]
\end{aligned}
$$

\section{RESULTS AND DISCUSSION}

Excitation matrix: We can write excitation matrix by the formally (Hashim, 2007):

$$
\overline{\mathrm{E}}^{\mathrm{i}} \cdot \hat{\mathrm{u}}_{\mathrm{r}}=-\frac{\mathrm{JW} \mu}{4 \pi \mathrm{r}} \exp \exp \left(-\mathrm{JK}_{0} \mathrm{r}\right)\left[\mathrm{R}_{\mathrm{n}}\right]\left[\mathrm{I}_{\mathrm{n}}\right]
$$

The $I_{n}$ is the coefficient of the expansion function:

$$
\begin{gathered}
{\left[\mathrm{R}_{\mathrm{n}}\right]=\left[\left[\mathrm{R}_{\mathrm{n}}^{\mathrm{t}}\right],\left[\mathrm{R}_{\mathrm{n}}^{\varnothing}\right]\right]} \\
{\left[\mathrm{R}_{\mathrm{n}}^{\mathrm{t}}\right]=\left[<\overline{\mathrm{E}}^{\mathrm{r}}, \overline{\mathrm{E}}_{\mathrm{nj}}^{\mathrm{t}}\right]}
\end{gathered}
$$

For the $\theta$-polarized plane wave $\left(\hat{\mathrm{u}}_{\mathrm{r}} \hat{\mathrm{u}}_{\mathrm{r}}{ }^{\theta}\right)$ :

$$
\begin{aligned}
& {\left[\mathrm{R}_{\mathrm{n}}^{\mathrm{t} \theta}\right]=\left[<\overline{\mathrm{E}}_{\theta}^{\mathrm{r}}, \overline{\mathrm{J}}_{\mathrm{nj}}^{\mathrm{t}}\right]} \\
& {\left[\mathrm{R}_{\mathrm{n}}^{\varphi \theta}\right]=\left[<\overline{\mathrm{E}}_{\theta}^{\mathrm{r}}, \overline{\mathrm{J}}_{\mathrm{nj}}^{\varphi}\right]} \\
& {\left[\mathrm{R}_{\mathrm{n}}^{\mathrm{t} \varnothing}\right]=\left[<\overline{\mathrm{E}}_{\varphi}^{\mathrm{r}}, \overline{\mathrm{J}}_{\mathrm{nj}}^{\mathrm{t}}\right]} \\
& {\left[\mathrm{R}_{\mathrm{n}}^{\varphi \varnothing}\right]=\left[<\overline{\mathrm{E}}_{\varphi}^{\mathrm{r}}, \overline{\mathrm{J}}_{\mathrm{nj}}^{\varphi}\right]}
\end{aligned}
$$

For the $\varphi$-polarized plane wave $\left(\hat{\mathrm{u}}_{\mathrm{r}} \hat{\mathrm{u}}_{\mathrm{r}}^{\theta}\right)$ :

$$
\left[I_{n}\right]=\left[Y_{n}\right]\left[V_{n}\right]
$$

As the matrix can be obtained from the inverse of the total matrix [Z] (Mautz and Harrington, 1969):

$$
\begin{gathered}
{\left[\mathrm{Y}_{\mathrm{n}}\right]=\left[\begin{array}{cc}
\mathrm{Y}_{\mathrm{n}}^{\mathrm{tt}} & \mathrm{Y}_{\mathrm{n}}^{\mathrm{t} \varnothing} \\
\mathrm{Y}_{\mathrm{n}}^{\varnothing \mathrm{t}} & \mathrm{Y}_{\mathrm{n}}^{\varnothing \varnothing}
\end{array}\right]} \\
{\left[\begin{array}{c}
\mathrm{I}_{\mathrm{n}}^{\mathrm{t}} \\
\mathrm{I}_{\mathrm{n}}^{\varphi}
\end{array}\right]=\left[\begin{array}{cc}
\mathrm{Y}_{\mathrm{n}}^{\mathrm{tt}} & \mathrm{Y}_{\mathrm{n}}^{\mathrm{t} \varnothing} \\
\mathrm{Y}_{\mathrm{n}}^{\varnothing \mathrm{t}} & \mathrm{Y}_{\mathrm{n}}^{\varnothing \varnothing}
\end{array}\right]\left[\begin{array}{c}
\mathrm{V}_{\mathrm{n}}^{\mathrm{t}} \\
\mathrm{V}_{\mathrm{n}}^{\varphi}
\end{array}\right]} \\
{\left[\begin{array}{c}
\mathrm{E}_{\theta}^{\mathrm{s}} \\
\mathrm{E}_{\varphi}^{\mathrm{s}}
\end{array}\right]=-\frac{J \mathrm{w} \mu}{4 \pi \mathrm{r}_{0}} \mathrm{e}^{-\mathrm{JK} \mathrm{K}_{0} \mathrm{r}_{0}} \sum_{\mathrm{j}=1}^{\mathrm{n}-1}\left[\begin{array}{ll}
\mathrm{R}_{\mathrm{nj}}^{\mathrm{t} \theta} & \mathrm{R}_{\mathrm{nj}}^{\mathrm{t} \varphi} \\
\mathrm{R}_{\mathrm{nj}}^{\mathrm{t} \varphi} & \mathrm{R}_{\mathrm{nj}}^{\phi \varphi}
\end{array}\right]\left[\begin{array}{c}
\mathrm{I}_{\mathrm{nj}}^{\mathrm{t}} \\
\mathrm{I}_{\mathrm{nj}}^{\varphi}
\end{array}\right]}
\end{gathered}
$$


Calculate radar cross section: The RCS can be defined mathematically as follows:

$$
\left[\begin{array}{l}
E_{\theta}^{s} \\
E_{\varphi}^{s}
\end{array}\right]=\frac{e^{J K r}}{r}\left[\begin{array}{ll}
S^{\theta \theta} & S^{\theta \varphi} \\
S^{\varphi \theta} & S^{\varphi \varphi}
\end{array}\right]\left[\begin{array}{c}
E_{\theta}^{i} \\
E_{\varphi}^{i}
\end{array}\right]
$$

From equations above we get:

$$
\delta^{\mathrm{pq}}=4 \pi\left|\mathrm{S}^{\mathrm{pq}}\right|^{2}
$$

where, p, q represent $\varphi^{\theta}$, $\theta^{\varphi}$ and $\varphi \varphi, \delta^{\theta \theta}$ Refers to RCS measured in $\theta$-polarized with $\varphi=0, \delta^{\theta \varphi}$ Refers to RCS measured in $\varphi$-polarized with $\varphi=90$ (Tahir et al., 2015).

Practical side: We can choose the shape shown below for the purpose of studying the different cases that can be shown by the effect of the different dimensions of the conductive body (BOR) on the radar cross section.

Effect of cone angle ( $\boldsymbol{\alpha})$ : In this study, the effect of the different values of the cone angle, as shown in Fig. 4 in all cases the Length $\mathrm{L}_{\text {tot }}$ will be constant:

$$
\begin{gathered}
\mathrm{L}_{\text {tot }}=1.5 \lambda \\
\mathrm{L}_{\text {tot }}=\mathrm{Z}_{\mathrm{c}}+\mathrm{L}_{\mathrm{c}} \\
\mathrm{Z}_{\mathrm{c}}=\frac{\mathrm{a}}{\tan \tan \alpha}, \mathrm{a}=0.2 \lambda, \alpha-\text { variable } \\
\mathrm{L}_{\mathrm{c}}=\left(1.5-\mathrm{Z}_{\mathrm{c}}\right) \lambda
\end{gathered}
$$

From relationships above can calculate the value of $\tan \alpha, Z_{c}, \mathrm{~L}_{\mathrm{c}}$ (Table 1):

We can observe from Fig. 5 that this part has a clear effect on calculation of (RCS) in E-plane with regarded to the cone angle when the angle is limited between 30 and $75^{\circ}$. With the length still of the body constant and equal to $1.5 \lambda$ and note that the effect is very clear when the value of the angle between 30 and $80^{\circ}$ and when larger value of the angle, the shape is approaching the shape of the cylinder (capsule).

Effect of body Length $\left(\mathbf{L}^{\mathrm{c}}\right)$ : In this study, the effect of the length of the conductive body shown in Fig. 4 will be studied on the radar cross section.

In this test the angle of cone $\left(\alpha=60^{\circ}\right)$ is fixed and total length of the body equal to $1.5 \lambda$, figure shows the result of RCS component in the E-plane $(\varphi=0)$.

If we return to our model, we find that there are several possibilities to achieve the value and form of the RCS but here we briefly review some of the possibilities because of the existence of a large number of possibilities in this aspect which enable to clarify some of the effects as follows:

In Fig. 6, it is found that the shape of the radar cross section is the same and it is different in the height and the

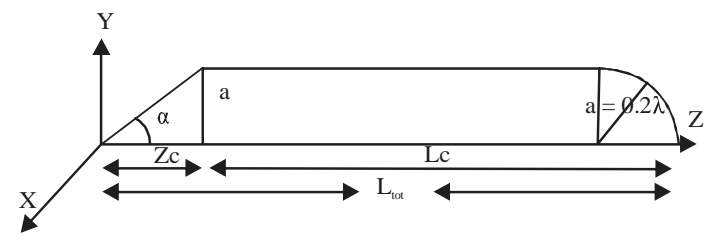

Fig. 4: Suggested conductor body of revolution

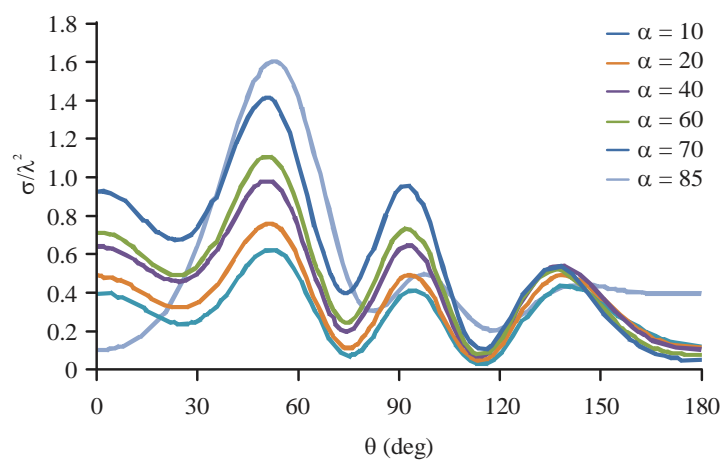

Fig. 5: Effect the cone angle on RCS for the body in E-plane

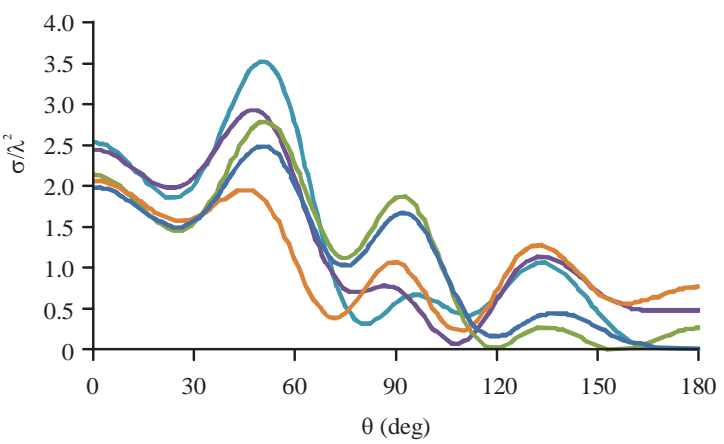

Fig. 6: Effect the body length on RCS in E-plane

\begin{tabular}{lccc}
\multicolumn{5}{l}{ Table 1: Shows the calculation the value $\tan \alpha, \mathrm{Zc}, \mathrm{L}_{\mathrm{c}}$} \\
\hline$\alpha(\mathrm{deg})$ & $\tan \alpha$ & $\mathrm{Zc}$ & $\mathrm{L}_{\mathrm{c}}$ \\
\hline 10 & 0.176 & 1.136 & 0.364 \\
20 & 0.363 & 0.551 & 0.949 \\
30 & 0.577 & 0.346 & 1.154 \\
40 & 0.839 & 0.238 & 1.262 \\
50 & 1.191 & 0.168 & 1.332 \\
60 & 1.732 & 0.115 & 1.385 \\
70 & 2.747 & 0.073 & 1.427 \\
80 & 5.671 & 0.035 & 1.465 \\
\hline
\end{tabular}

decrease in the peaks that are curved the radar cross section. The maximum height of the peaks between the angle 30 and $60^{\circ}$ nearly.

\section{CONCLUSION}

Radar cross section is the area where a quantity of electromagnetic energy falls on it and reflects it equally in all directions. There is no relationship between the shape 
of the target and radar section but greater the area of the target increased the radar cross section and the less the area of the target less radar cross section. Two types of tests were performed on the proposed body. The first test is the angle effect $(\alpha)$. The second test is the body Length $\left(L_{c}\right)$. The effects of each of the two test were studied on the radar cross section and it was found that there was an effect on the Radar Cross Section (RCS).

\section{REFERENCES}

Areebi, N.A., 2016. Computation of radiation from wire antennas on, or near, conducting bodies of translation. J. Kufa Phys., 8: 88-99.

Boadu, E.O., K.K. Mireku and K. Gbongli, 2017. Physical optics and the impedance boundary condition. Am. J. Eng. Res., 6: 17-29.

Divyalakshmi, A., A. Bhuvana and G. venlat Babu, 2018. Analysis of radar cross section and detection. Int. J. Pure Appl. Math., 119: 469-477.

Hamham, E.M., A. Zugari and A. Benali, 2017. Calculating radar cross section of lossy targets using the surface impedance approach. Prog. Electromagnet. Res., 55: 13-24.

Hashim, A., 2007. Moment method solution for scattering problems from perfectly conducting bodies of revolution. J. Karbala Univ., 5: 10-22.

Huddleston, P., L. Medgyesi-Mitschang and J. Putnam, 1986. Combined field integral equation formulation for scattering by dielectrically coated conducting bodies. IEEE. Trans. Antennas Propag., 34: 510-520.

Khan, J., W. Duan and S. Sherbaz, 2012. Radar cross section prediction and reduction for naval ships. J. Mar. Sci. Appl., 11: 191-199.

King, R. and C. Harrison, 1971. Scattering by imperfectly conducting spheres. IEEE. Trans. Antennas Propag., 19: 197-207.
Kong, M., M.S. Chen, L. Zhang, X.Y. Cao and X.L. Wu, 2016. Efficient solution to electromagnetic scattering problems of bodies of revolution by compressive sensing. Chin. Phys. Lett., Vol. 33, 10.1088/0256307X/33/1/018402.

Kumar, A. and V. Dangi, 2016. Electromagnetic spectrum and its impact on human life. Intl. J. Res. Educ. Sci. Methods, 4: 67-72.

Madheswaran, M. and P.S. Kumar, 2012. Estimation of wide band Radar Cross Section (RCS) of regular shaped objects using Method of Moments (MOM). ICTACT. J. Commun. Technol., 3: 536-541.

Mautz, J.R. and R.F. Harrington, 1969. Radiation and scattering from bodies of revolution. Appl. Sci. Res., 20: 405-435.

Medgyesi-Mitschang, L. and D.S. Wang, 1983. Hybrid solutions for scattering from perfectly conducting bodies of revolution. IEEE. Trans. Antennas Propag., 31: 570-583.

Rao, G.S.B., S. Nambari, S. Kota and K.R. Rao, 2017. Monostatic radar cross section estimation of missile shaped object using physical optics method. IOP Conf. Ser. Mater. Sci., Vol. 225, 10.1088/1757899X/225/1/012278.

Resende, U.C., F.J. Moreira, J.R. Bergmann and S.T. Goncalves, 2015. Evaluation of electromagnetic scattering by conducting bodies of revolution with discontinuous currents. IEEE. Trans. Magn., 52: 1-4.

Rui, X., J. Hu and Q.H. Liu, 2010. Fast inhomogeneous plane wave algorithm for analysis of composite bodies of revolution. Prog. Electromagnet. Res., 108: 235-247.

Sevgi, L., Z. Rafiq and I. Majid, 2013. Radar Cross Section (RCS) measurements [Testing ourselves]. IEEE. Antennas Propag. Mag., 55: 277-291.

Tahir, A.S., A.G. Wa'il and A.H. Abood, 2015. Electromagnetic scattering from dielectric bodies of revolution with attached wires. Basrah J. Sci., 33: 90-109. 